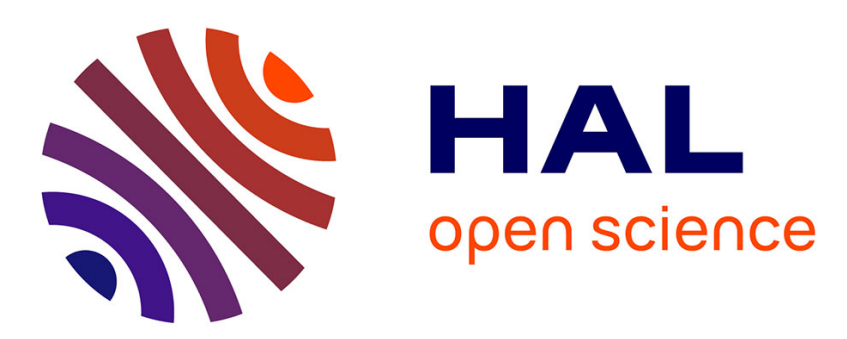

\title{
Inequity and Risk Aversion in Sequential Public Good Games
}

\author{
Sabrina Teyssier
}

\section{To cite this version:}

Sabrina Teyssier. Inequity and Risk Aversion in Sequential Public Good Games. 2009. halshs00422669

\section{HAL Id: halshs-00422669 \\ https://shs.hal.science/halshs-00422669}

Submitted on 8 Oct 2009

HAL is a multi-disciplinary open access archive for the deposit and dissemination of scientific research documents, whether they are published or not. The documents may come from teaching and research institutions in France or abroad, or from public or private research centers.
L'archive ouverte pluridisciplinaire HAL, est destinée au dépôt et à la diffusion de documents scientifiques de niveau recherche, publiés ou non, émanant des établissements d'enseignement et de recherche français ou étrangers, des laboratoires publics ou privés. 


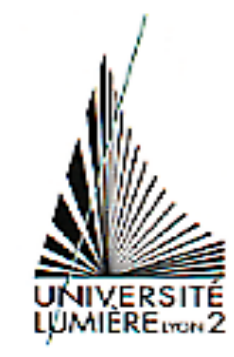

DOCUMENTS DE TRAVAIL - WORKING PAPERS

W.P. 09-19

\title{
Inequity and Risk Aversion \\ in Sequential Public Good Games
}

\author{
Sabrina Teyssier
}

Septembre 2009

GATE Groupe d'Analyse et de Théorie Économique UMR 5824 du CNRS

93 chemin des Mouilles - 69130 Écully - France

B.P. $167-69131$ Écully Cedex

Tél. +33 (0)4 72866060 - Fax +33 (0)4 72866090

Messagerie électronique gate@gate.cnrs.fr

Serveur Web : www.gate.cnrs.fr 


\title{
Inequity and Risk Aversion
}

\section{in Sequential Public Good Games*}

\author{
Sabrina Teyssier ${ }^{\dagger}$
}

September 2009

\begin{abstract}
This paper analyzes which type of intrinsic preferences drive an agent's behavior in a sequential public good game depending on whether the agent is first or second mover. Theoretical predictions are based on heterogeneity of individuals in terms of social and risk preferences. We modelize preferences according to the inequity aversion model of Fehr and Schmidt (1999) and to the assumption of constant relative risk aversion. Risk aversion is significantly and negatively correlated with the contribution decision of first movers. Second movers with sufficiently high advantageous inequity aversion free-ride less and reciprocate more than others. Both results are predicted by our model. Nevertheless, no effect of disadvantageous inequity aversion of first movers is found in the data while theory predicted it. Our results underline the importance of taking into account the order of agents' play to correctly understand which type of preferences influences cooperation in voluntary contribution mechanisms. They suggest that individuals' behavior can be consistent between different experimental games.
\end{abstract}

JEL classification: C72, C91, D63, D81, H41.

Keywords: inequity aversion, risk aversion, public good game, conditional contribution.

*I am grateful to Katharine Bendrick, Lisa Bruttel, Urs Fischbacher, Franziska Heusi, Simeon Schudy, Verena Utikal, Marie Claire Villeval and participants at the 5th International Meeting on Experimental and Behavioral Economics for helpful comments and suggestions. Financial support from the French Agency of Research - project "Experiments on Motivation, Incentives and Rationality" (ANR-EMIR) is gratefully acknowledged.

†Thurgau Institute of Economics, Kreuzlingen, Switzerland; University of Konstanz, Department of Economics, Germany. Email: teyssier@twi-kreuzlingen.ch 


\section{Introduction}

Understanding individuals' behavior in voluntary contribution mechanisms has wide implications because many economic situations depend on people's actions toward public goods. The public good game has been extensively used in experimental economics in the last twenty years to study this type of issue. Most of this literature is about simultaneous contributions of agents, while a sequential public good game would better characterize real situations. Indeed, most of the time, some people are pioneers of an action and some others are followers in the sense that they perform an action only if some people already performed this action earlier. Knowing which intrinsic preferences drive the decision of agents to contribute to a public good would help to design appropriate economic policies. It is necessary to know which type of agents would contribute more as a pioneer and which type would contribute more as a follower to determine who should benefit from information transparency and how incentives should be structured.

The aim of this paper is to determine by a laboratory experiment whether social preferences or risk preferences drive the contribution decision of agents in a sequential public good game. According to previous economic literature, social preferences and risk preferences are the most relevant determinants of contributions to a public good.

On the one hand, a robust result in the literature is that an important share of people voluntarily cooperate even though the Nash equilibrium is to contribute nothing to the public good (see Ledyard, 1995, for a review). It is found that both selfish people and cooperators exist. The observation of non-selfish behavior has led to the emergence of different theories considering other-regarding preferences (see Sobel, 2005, for a review). ${ }^{1}$ If all agents are selfish, the unique equilibrium is to free-ride. Although the social optimum is to fully contribute to the public good, selfish agents always have an interest to deviate from the optimum to maximize their own utility function and to contribute less. However, when loosening the homo-œeconomicus hypothesis, i.e. assuming that either all agents have social preferences or agents are heterogeneous in these preferences, the free-riding equilibrium is not unique. Cooperative behavior, leading to higher socially effective outcomes, is also an

\footnotetext{
${ }^{1}$ These theories on fairness explain the positive average rate of contributions in public good games by the integration of others' behavior or payoffs in their utility function. Some models include distributive consequences of actions (Fehr and Schmidt, 1999, Bolton and Ockenfels, 2000) while others are based on fairness intentions (Rabin, 2003, Dufwenberg and Kirchsteiger, 2004). Falk and Fischbacher (2006) consider both intentions and outcome distributions to drive decisions of people in situations with strategic interaction.
} 
equilibrium behavior when some people have social preferences.

On the other hand, it is found that risk aversion negatively affects an agent's contribution when the decision to contribute is made under strategic uncertainty. ${ }^{2}$ Assuming that some agents have social preferences, first movers in a sequential public good game must face strategic uncertainty. Indeed, they do not know the decision of second movers as both free-riding and conditional contribution can be equilibrium decisions. Bohnet and Zeckhauser (2004) and Schechter (2007) link risk aversion with agents' behavior in trust games and Heinemann, Nagel and Ockenfels (2004) analyze risk aversion in coordination games. Therefore, in the presence of strategic uncertainty in a public good, contributions might be affected by risk preferences of agents. Additionally, beliefs about the others' contribution to the public good are shown to have a significant and positive effect on contribution decisions of agents (Orbell and Dawes, 1991, Offerman, 1997, Croson, 1998, Offerman, Sonnemans and Schram, 1996, 2001). Although it is not the object of our study, we control for the effect of beliefs on the contribution decision of agents.

In the current paper, we consider a sequential public good game with two agents and we elicit agents' preferences. In the sequential public good game, the first mover does not know the contribution of the second mover while the second mover observes the decision of the first mover before making his choice. The first mover decides on a contribution to the public good among integers. The second mover chooses between two options: for every potential contribution of the first mover, he can either contribute the same amount as the first mover or contribute nothing. This limited choice has been chosen to make the game as simple as possible and to allow for clear theoretical predictions depending on intrinsic preferences.

Regarding social preferences, we analyze in the current paper the effect of inequity aversion as defined by Fehr and Schmidt (1999). The advantage of this model is that the inequity aversion level measured in one game can be applied in other games; it assumes that inequity aversion in one game is just a monotonic transformation of thresholds in another game. Therefore, we can measure inequity preferences in games that are independent from the public good game and infer the effect of inequity preferences. ${ }^{3}$ The measure

\footnotetext{
${ }^{2}$ Strategic uncertainty refers to a situation in which uncertainty is due to the lack of information about others' behavior.

${ }^{3}$ Some studies indicate that fairness depends on intentions and then on the context. See for example, Falk, Fehr and Fischbacher (2003), McCabe, Rigdon and Smith (2003), and Falk and Fischbacher (2006), for an overview.
} 
of individuals' inequity aversion in experiments is still not common yet. Therefore, the games we use to elicit both advantageous and disadvantageous inequity aversion are based on the design proposed by Blanco, Engelmann and Normann (2007) to control for some robustness in our results. We elicit agents' advantageous inequity aversion by a modified dictator game and agents' disadvantageous inequity aversion by the ultimatum game (Güth, Schmittberger and Schwarze, 1982), using the strategy method (Selten, 1967). Risk aversion is elicited through the classic Holt and Laury's lottery (2002) assuming constant relative risk aversion.

Due to our simple design, theoretical predictions are clear. Risk aversion and disadvantageous inequity aversion should negatively affect the contribution amount of the first mover. The second mover should contribute the same amount as the first mover if he is sufficiently advantageous inequity averse.

Our first result is that the contribution amount of the first mover is significantly and negatively affected by risk aversion. Disadvantageous inequity aversion has no significant effect. The second result concerns the second mover. We found that the second mover is significantly more likely to contribute the same amount as the first mover and less likely to free-ride if he is sufficiently advantageous inequity averse, as suggested by theory. Risk aversion has no effect here.

It is not obvious in the literature whether inequity aversion theory helps to explain agents' contributions in a simultaneous public good game, i.e. under strategic uncertainty. Blanco, Engelmann and Normann (2007) find that the inequity aversion of subjects can explain their behavior in public good games but only at the aggregate level whereas Dannenberg, Riechmann, Sturm and Vogt (2007), using the same games to measure agents' preferences, find a significant positive effect of advantageous inequity aversion on the agents' contribution in the public good. Our result showing that advantageous inequity aversion is the main determinant of the second mover's conditional contribution adds to this debate. It suggests that any type of uncertainty must be taken apart to accurately evaluate the effect of social preferences. We deduce that predictions of the Fehr and Schmidt model (1999) are mainly validated by our data when the situation is free of any uncertainty. Finally, a suggestion arising from our results is that individuals' behavior is consistent between different experimental games.

The paper is organized as follows. Section 2 explains the game and theoretical predic- 
tions. Section 3 presents the experimental design. The results are analyzed in Section 4. Section 5 concludes.

\section{Game and theoretical predictions}

\subsection{Sequential public good game}

Suppose two agents play a sequential public good game. The first mover, mover 1, decides on the amount he wants to contribute to the public good. To keep the game as simple as possible and to obtain clear predictions regarding the effect of both risk and inequity aversion, the second mover, mover 2, makes a choice between two options: contributing the same amount as the first mover or free-riding by contributing nothing. The additional advantage of this structure of the game is that it allows us to separate the effect of advantageous and disadvantageous inequity aversion. Indeed, the first mover can earn a payoff lower or equal to the second mover's payoff while it is the opposite for the second mover. The second mover can earn a payoff higher or equal to the first mover's payoff.

The payoff function follows the basic public good game framework. The marginal return of the public good is $a$, with $a \in[0,1]$ and each agent's initial endowment is $E$. The payoff function of player $k, k=1$ for the first mover and $k=2$ for the second mover, is defined as follows:

$$
R_{k}=E-x_{k}+a\left(x_{k}+x_{-k}\right)
$$

with $k=1,2$ and $-k=1$ if $k=2,-k=2$ if $k=1$. $R_{k}$ is the payoff of mover $k$ and $x_{k}$ and $x_{-k}$ are the contributions to the public good of mover $k$ and mover $-k$, respectively. The contribution decision of the first mover is an integer defined as $x_{1} \in[0,10]$ and the contribution decision of the second mover can take two values $x_{2} \in\left\{0, x_{1}\right\}$.

Using von-Neumann and Morgenstern utility functions and considering both risk and inequity aversion of agents, the utility function of agent $i$ as mover $k$ is written:

$$
U_{i k}=v_{i}\left(u_{i}\left(R_{k}\right)\right)
$$

with $u_{i}(\cdot)$ the utility function integrating inequity preferences of agent $i$ in role of mover $k$ and $v_{i}(\cdot)$, the utility function taking into account risk preferences of agent $i$ in role of mover $k$. 
We characterize inequity preferences as defined by Fehr and Schmidt (1999). Inequity preferences are integrated in the following utility function:

$$
u_{i}\left(R_{k}\right)=R_{k}-\alpha_{i} \max \left\{R_{-k}-R_{k}, 0\right\}-\beta_{i} \max \left\{R_{k}-R_{-k}, 0\right\}
$$

$\alpha_{i}$ represents the disadvantageous inequity aversion of agent $i$ while $\beta_{i}$ corresponds to his advantageous inequity aversion. According to Fehr and Schmidt (1999), $\alpha_{i} \geq 0$ and $0 \leq \beta_{i}<1$. A selfish agent is an agent who does not take into account others' payoffs in his utility function, i.e. $\alpha=\beta=0$. An inequity averse agent can be negatively affected by having less than the other subject, $\alpha>0$, or by having more, $\beta>0$, or both.

To represent risk preferences of agent $i$, the function $v_{i}(\cdot)$ assumes constant relative risk aversion. It is defined as follows:

$$
v_{i}\left(u_{i}\left(R_{k}\right)\right)=\frac{\left[u_{i}\left(R_{k}\right)\right]^{1-r_{i}}}{1-r_{i}}
$$

Agent $i$ is risk neutral if $r_{i}=0$, risk averse if $r_{i}>0$ and risk lover if $r_{i}<0{ }^{4}$

We do not assume identical intrinsic preferences between subjects. Subjects are heterogeneous in terms of both inequity aversion and risk aversion.

\subsection{Theoretical predictions}

We solve this game by backward induction, determining first the optimal behavior of the second mover and then the optimal contribution of the first mover. The parameters in our experiment are such that $E=10$ and $a=0.8 .^{5}$

Second mover's choice The second mover maximizes his utility function to determine whether he plays $x_{2}=0$ or $x_{2}=x_{1}$. As he can only choose between contributing nothing or contributing the same amount as the first mover, the second mover can never earn less than the first mover, $R_{2} \geq R_{1}$. Therefore, regarding inequity preferences, only advantageous inequity aversion is relevant in the second mover's utility function. Therefore, the utility

\footnotetext{
${ }^{4} \mathrm{As}$ in Holt and Laury (2002), the division by $\left(1-r_{i}\right)$ is used to allow an increasing utility function when $r_{i}>1$. When $r=1$, the natural logarithm is used.

${ }^{5}$ The social marginal return of the public good is 1.6 which is common in experiments. As there are two players, the individual marginal return of the public good is 0.8 .
} 
function of second mover $i$ is as follows:

$$
U_{i 2}=\frac{\left[10-x_{i 2}+0.8\left(x_{1}+x_{i 2}\right)-\beta_{i}\left(x_{1}+x_{i 2}\right)\right]^{1-r_{i}}}{1-r_{i}}
$$

By maximization of the second mover's utility function, we find that he should contribute to the public good the same amount as the first mover if his degree of advantageous inequity aversion is such that $\beta_{i} \geq 0.2$. The equilibrium decision of the second mover is written:

$$
x_{i 2}^{*}= \begin{cases}0 & \text { if } \beta_{i}<0.2 \\ x_{1} & \text { if } \beta_{i} \geq 0.2\end{cases}
$$

This means that the second mover should contribute the same amount as the first mover whatever this amount. Risk aversion should have no effect.

First mover's choice Under standard economic assumptions, a first mover should never contribute, assuming that second movers always shirk. Nevertheless, as soon as the first mover believes that some people playing as second movers have intrinsic preferences such as $\beta \geq 0.2$, the optimal behavior of the first mover may be different from the standard economic prediction: The first mover may contribute more than nothing to the public good. Therefore, beliefs of the first mover about the type, i.e. value of $\beta$, of the second mover are needed to construct the utility function of the first mover. Depending on the choice of the second mover, the first mover may earn an equal or lower payoff than second mover. Thus, regarding inequity preferences, only the first mover's disadvantageous inequity aversion affects his utility; advantageous inequity aversion has no effect.

Moreover, the first mover must maximize his expected utility because of the strategic uncertainty he faces as soon as he believes in the existence of some conditional contributors, i.e. $\beta \geq 0.2$ in our framework. As the first mover does not know the type of the second mover, contributing a high amount to the public good game is more risky than contributing a low amount. Indeed, if the first mover contributes a high amount, his loss if the second mover contributes nothing instead of the same amount as the first mover is higher than if he had contributed a low amount. The spread between the first mover's potential payoffs, depending on the choice of the second mover, is increasing with his contribution level to the public good. Therefore, the risk in the game played by the first mover is increasing with his contribution to the public good. The first mover $i$ maximizes the following expected 
utility function:

$$
E U_{i 1}=\frac{p_{i}\left(10-\left(0.2+\alpha_{i}\right) x_{1}\right)^{1-r_{i}}+\left(1-p_{i}\right)\left(10+0.6 x_{1}\right)^{1-r_{i}}}{1-r_{i}}
$$

with $p_{i}$, the belief of agent $i$ about his probability to be matched with a second mover being not advantageous inequity averse, $\beta<0.2$, and $1-p_{i}$ his probability to be matched with a second mover having sufficiently high disadvantageous inequity aversion, $\beta \geq 0.2{ }^{6}$

The first order condition is as follows:

$$
p_{i}\left(-0.2-\alpha_{i}\right)\left(10-\left(0.2+\alpha_{i}\right) x_{1}\right)^{-r_{i}}+\left(1-p_{i}\right) 0.6\left(10+0.6 x_{1}\right)^{-r_{i}}=0
$$

Due to the complexity of the solution, we represent the optimal contribution of the first mover on the following graphs. As we concentrate more on the effect of inequity and risk aversion, we represent the optimal contribution depending on disadvantageous inequity aversion and risk aversion for some specific values of the first mover's beliefs on the second mover's type, $p_{i}=0.1, p_{i}=0.5$ and $p_{i}=0.9$. The optimal behavior of agents depending on the degree of their intrinsic preferences is then easily deduced.

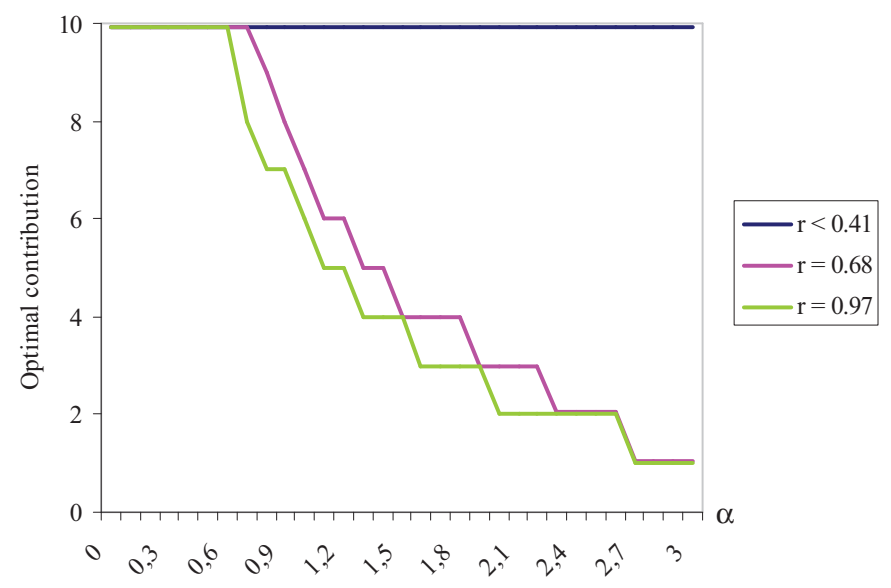

Figure 1: Optimal contribution depending on $\alpha$ and $r$ when $p=0.1$

\footnotetext{
${ }^{6} E U_{i 1}$ is defined only for $\left(10-\left(0.2+\alpha_{i}\right) x_{1}\right)>0$. Then, depending on the value of $\alpha_{i}$, the range of $x_{1}$ is more or less spread.
} 


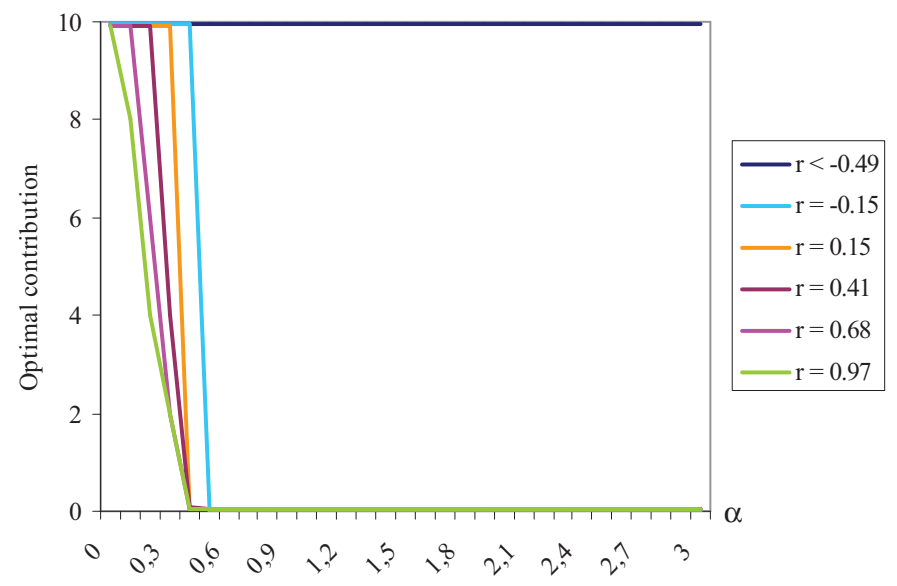

Figure 2: Optimal contribution depending on $\alpha$ and $r$ when $p=0.5$

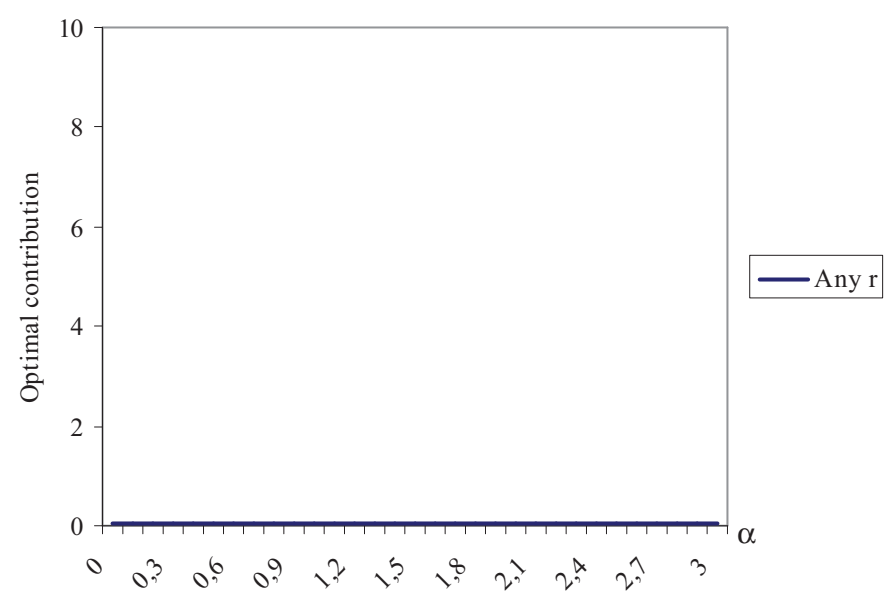

Figure 3: Optimal contribution depending on $\alpha$ and $r$ when $p=0.9$

It is clear from the figures that the optimal contribution of the first mover is lower for agents with a high degree of disadvantageous inequity aversion and for agents with a high degree of risk aversion. Moreover, the crossing effect of disadvantageous inequity aversion and risk aversion is that agents with high risk aversion should contribute a lower amount to the public good for the same degree of disadvantageous inequity aversion than other agents. Beliefs of the first mover about others play a strong role in the decision process. A first mover who thinks that his chances to be matched with a second mover who will contribute the same amount as him instead of free-riding are strong should contribute a higher amount to the public good. We note about figure 3 that if the first mover thinks that his probability to be matched with a second mover who will contribute the same amount as him is equal to $10 \%$, he will always contribute zero to the public good whatever 
his intrinsic preferences. Although the effect of beliefs is not the main interest of our study, we must take beliefs into account regarding the analysis of the first mover's behavior.

To summarize, in addition to expectations on the other agent's behavior, disadvantageous inequity aversion and risk aversion should influence the decision of the first mover. The second mover should only be influenced by his advantageous inequity aversion to make his choice. Theoretical predictions on the effect of intrinsic preferences of agents on their contribution to the public good as first or second mover are summarized in table 1.

\begin{tabular}{lcc}
\hline \hline & $1^{\text {st }}$ mover & $2^{\text {nd }}$ mover \\
\hline $\begin{array}{l}\text { Disadvantageous } \\
\text { inequity aversion } \\
\begin{array}{l}\text { Advantageous inequity } \\
\text { aversion }(\beta \geq 0.2)\end{array}\end{array}$ & Negative & None \\
Risk aversion & Negative & Positive \\
\hline
\end{tabular}

Table 1: Predicted effect of intrinsic preferences on first and second movers' contribution

Predictions of contribution decisions based on intrinsic preferences differ between first and second movers due to the vanishing of strategic uncertainty. The analysis of the second mover's behavior additionally allows us to determine how much the choice of reciprocating is driven by advantageous inequity aversion when it is predicted to be the only determinant at stake. It adds another test of the model of inequity aversion of Fehr and Schmidt (1999) for the case when any type of uncertainty has vanished. It leads to a test of the pure effect of social preferences that has not yet been done in the literature.

\section{Experimental design}

The experiments were conducted at the GATE Institute, Lyon, France. The experiment was computerized using the Regate software (Zeiliger, 2000). We recruited 118 under graduate students from three business or engineering schools by using ORSEE software (Greiner, 2004). Six experimental sessions were run. The instructions are provided in the appendix. 
For every session, all participants were randomly assigned to a computer. The instructions informed participants that all of them would take part in four different games, one

being the Holt and Laury lottery (2002). They were not aware of which type of game they were to play. They had to play three independent games to elicit preferences first and then a one-shot sequential public good game. The subjects received no feedback during the session.

Instructions for each game were distributed once the previous game was completed and were read aloud. Questions were answered in private. The participants had to answer a series of questions for each game to verify their understanding of the instructions. Each game started once all the participants answered correctly. No communication was allowed.

The exchange rate was 4 points $=€ 1$. The presentation of the Holt and Laury lottery (2002) was directly in euros. The payment consisted of the payoff in the lottery, plus the payoff in one of the three other games, randomly selected by the program, plus a $€ 3$ show-up fee. Sessions lasted around 60 minutes and the average earning was $€ 8.14$.

\subsection{Public good game}

We organized a one-shot sequential public good game with two players and we used the strategy method (Selten, 1967). Our framework is close to Fischbacher and Gächter (2009). All subjects had two types of decision to make. First, every subject, as the first mover, was asked to decide which amount of the 10 points he wanted to contribute to the public good. The second decision all subjects were required to make was as the second mover and concerned conditional contribution. Ten situations were presented to every subject. In each situation, the contribution of the first mover was written. To keep the design as simple as possible and to be able to accurately test theoretical predictions, the decision of the second mover consisted of a choice between contributing the same amount as the first mover and contributing nothing. For example, in decision 1, the second mover had to choose whether he wanted to contribute 0 points or 1 point to the public good when the other subject contributed 1 point. In decision 2 , the choice was made between a contribution of 0 points and a contribution of 2 points when the other agent contributed 2 points and so on until decision 10 .

Payoffs were determined as follows. Once all subjects had made their decisions as the first mover and as the second mover, the software randomly selected half of the subjects to 
be in the role of the first mover and the other half to be in the role of the second mover. For a subject in the role of the first mover, it was his choice as first mover that was considered for the computation of the payoffs. For a subject in the role of the second mover, it was his choice as second mover for the actual contribution of the first mover that was considered. Subjects were matched in pairs. Every pair consisted of one subject in the role of the first mover and one subject in the role of the second mover. The payoffs were then calculated according to the payoff function in equation (1).

\subsection{Elicitation of preferences}

Three games, independent of the sequential public good game, were played to evaluate subjects' preferences, i.e. advantageous and disadvantageous inequity aversion and risk aversion. The strategy method (Selten, 1967) was also used here.

Advantageous inequity aversion The measure of advantageous inequity aversion is based on the design of Blanco, Engelmann and Normann (2007). Subjects were asked to participate in a series of dictator games. The game involves two roles: the dictator and the receiver. All subjects made their decisions under both roles before knowing the actual role they had been allocated for payment. At the end of the session, the computerized program randomly allocated a role to each subject and payoffs were determined accordingly. Half of the subjects were dictators and the other half were receivers. All subjects were matched such that there were a dictator and a receiver in each pair.

The rules of the game were the following. The dictator made a choice between two options regarding the distribution of a pie between himself and the receiver. 21 decisions were presented to the subjects. The first option, option $a$, corresponds to the equal share for the dictator and the receiver: The distribution is $\left(z_{i}, z_{i}\right)$, with $z_{i}=\{0, \ldots, 20\}$. The second option, option $b$, is such that the dictator keeps 18 points for himself and gives 2 points to the receiver, distribution $(18,2)$. The 21 decisions are such that under decision 1, the dictator must choose between the distribution $(0,0)$ (0 for himself and 0 for the receiver) and the distribution $(18,2)$ (18 for himself and 2 for the receiver; under decision 2 , the choice is made between the distribution $(1,1)$ and the distribution $(18,2)$ and so on until decision 21 where the choice is made between the distribution $(20,20)$ and the distribution $(18,2)$. For the payment, one decision was randomly selected by the software. 
The dictator earned the amount he chose for himself in this decision.

Before playing as the dictator, subjects first made their decision as the receiver. Every receiver was asked to decide to play the game or to opt out for a fixed payment ( 5 points $^{7}$ ). The choice of the outside option by the receiver did not affect the gains of the dictator. When a dictator is matched with a receiver having chosen the outside option, he still earns the amount he chose for himself. This first step allows for a strategic dimension to the dictator game with a receiver not being entirely passive. The evaluation of the advantageous inequity aversion is then more easily associable with behavior in games with strategic interaction. ${ }^{8}$ Moreover, it allows limiting the problem of over-estimation of advantageous inequity aversion that might occur when dictators are obliged to be matched with a receiver. ${ }^{9}$ All subjects knew the rules of the game at the time they made their decision in the receiver's role. The payment of the receiver equaled 5 if he opted out and it equaled the amount the dictator chose for him in the selected decision if he decided to play the game.

The advantageous inequity aversion of agents, $\beta_{i}$, was estimated through the choices of subjects when they made their decisions in the dictator's role. It was calculated by the decision number at which the agent switched from option $b$ to option $a$, i.e. from the distribution $(18,2)$ to the equal distribution. The value of $\beta_{i}$ is determined by $U_{i}\left(z_{i}-0.5, z_{i}-0.5\right)=U_{i}(18,2)$, with $z_{i}$ being the decision number of the first decision in which the agent chooses option $a$. The value of $\beta_{i}$ is then defined below:

$$
\beta_{i}=\frac{18.5-z_{i}}{16}
$$

Selfish agents are expected to switch from option $b$ to option $a$ at the decision number 19. All agents switching before decision 16 have $\beta_{i} \geq 0.2$, all those switching after have $\beta_{i}<0.2$.

Disadvantageous inequity aversion Disadvantageous inequity aversion was measured as in Blanco, Engelmann and Normann (2007) through the ultimatum game (Güth, Schmit-

\footnotetext{
${ }^{7}$ Under the assumption that the dictator is selfish, the expected payoff of the receiver is around 5 points.

${ }^{8}$ Fehr and Schmidt (1999) underline that the dictator game allows measurement of advantageous inequity aversion but is limited due to the non-strategic character of such a game.

${ }^{9}$ Lazear, Malmendier and Weber (2006) show that dictators give a higher amount to receivers when dictators are obliged to be matched with a receiver compared to a situation where they can decide to be alone or matched with a receiver.
} 
tberger and Schwarze, 1982). The game involves two roles : the sender and the responder. All subjects made decisions under both roles before knowing the actual role they had. At the end of the session, the computerized program randomly allocated a role to each subject and payoffs were determined accordingly. Half of the subjects were allocated to the sender's role and half to the responder's role. All subjects were matched in pairs with a sender and a responder in each pair.

In the role of the sender, each subject received an endowment of 20 points. He was required to decide on the distribution of this amount between himself and the responder, knowing that the responder could either accept or reject this share. If the responder accepted the distribution, this distribution was implemented but if he rejected it, both the sender and the responder earned nothing. Then, the responder had to choose between two options for 21 decisions. Option $a$ is to accept the distribution and option $b$ is to reject it. Under decision 1, the responder had to choose between accepting the distribution $(20,0)$ (20 for the sender and 0 for the responder) and rejecting it; under decision 2, the choice was made between accepting the distribution $(19,1)$ and rejecting it and so on until decision 21 where the choice was made between accepting the distribution $(0,20)$ and rejecting it.

The responder's decisions allow us to measure the degree of disadvantageous inequity aversion, $\alpha_{i}$, of the subjects. The estimation of $\alpha_{i}$ is realized through the decisions of the responder by the decision number at which the agent switched from option $b$ to option $a$, i.e. for which distribution the subject switched from rejecting to accepting the distribution. The value of $\alpha_{i}$ is determined by $U_{i}\left(s_{i}-0.5,20.5-s_{i}\right)=U_{i}(0,0) 0$, with $s_{i}$ being the decision number of the first decision under which the subject accepted the distribution of the sender.

$$
\alpha_{i}=\frac{s_{i}-0.5}{21-2 s_{i}}
$$

In the responder's role, selfish agents should always accept the distribution proposed as soon as the share they receive is strictly positive. The later the agent switches from rejecting to accepting the distribution, the higher his value of $\alpha_{i}$.

Risk aversion To elicit risk aversion of subjects, we set up the commonly used lottery procedure of Holt and Laury (2002). The subjects filled in a questionnaire with 10 decisions. Each decision consists of a choice between two paired lotteries, option $a$ and option $b$. The payoffs for option $a$ are either $€ 2$ or $€ 1.60$, whereas the riskier option $b$ pays either $€ 3.85$ 
or $€$ 0.10. In the first decision, the probability of the high payoff for both options was 1/10. In the second decision, the probability increased to 2/10. Similarly, the chances of receiving the high payoff increased as the number of the decision increased. When the probability of the higher payoff is large enough, subjects should cross over from option $a$ to option $b .^{10}$ Risk neutrality corresponds to a switch at the fifth decision, while risk loving subjects are expected to move earlier and risk averse subjects later.

Beliefs As the impact of beliefs on contributions to a public good are not the main interest of our study, we absolutely wanted to avoid any influence of the elicitation of beliefs on the decisions of subjects in the public good game. We did not want to ask subjects directly whether they thought that the second mover would choose to contribute the same amount as them or to free-ride by contributing nothing. This question might have influenced the behavior of subjects. Therefore, we used a proxy. We asked each subject, after their decision as first mover and before their decision as second mover, "What amount do you think the other subject has chosen?". If the subject finds the right contribution of the other subject, he receives 1 additional point. ${ }^{11}$ Our measure is more about each subject's evaluation of the resemblance between himself and others. As the significant effect of beliefs on contributions has been shown to be robust in the literature (for example in Orbell and Dawes, 1991, Offerman, 1997, Croson, 1998, Offerman, Sonnemans and Schram, 1996, 2001), we can evaluate the robustness of our method.

\section{Results}

In this section, we analyze how subjects' behavior in the public good game are related to subjects' intrinsic preferences, playing as first or second mover. We present first how subjects differ in their intrinsic preferences by showing inequity aversion and risk aversion distributions among subjects.

\footnotetext{
${ }^{10}$ The number of safe choices corresponds to the number of decisions with option $a$, that is safer than option $b$, and thus corresponds to the "risk aversion" variable in our econometric analysis.

${ }^{11}$ We chose to reward good predictions on the other's contribution by a very small prize to apply the standard rules used in experimental economics. Nevertheless, this choice should not affect the results. Indeed, Gächter and Renner (2006) show that, in a public good experiment, the distribution of beliefs of individuals and the relationship between contributions and beliefs are unaffected by incentives.
} 


\subsection{Distribution of preferences}

Subjects are heterogeneous in their inequity aversion degrees. $17.8 \%$ of the 118 subjects are purely selfish $(\alpha=\beta=0)$ and $39.8 \%$ are averse to both advantageous and disadvantageous inequity aversion $(\beta>0$ and $\alpha>0)$. Advantageous and disadvantageous inequity aversion are not correlated (Spearman correlation test, $z=0.0265, p=0.7758) .{ }^{12}$ Figure 4 represents the distribution of subjects depending on both their advantageous and disadvantageous inequity aversion.

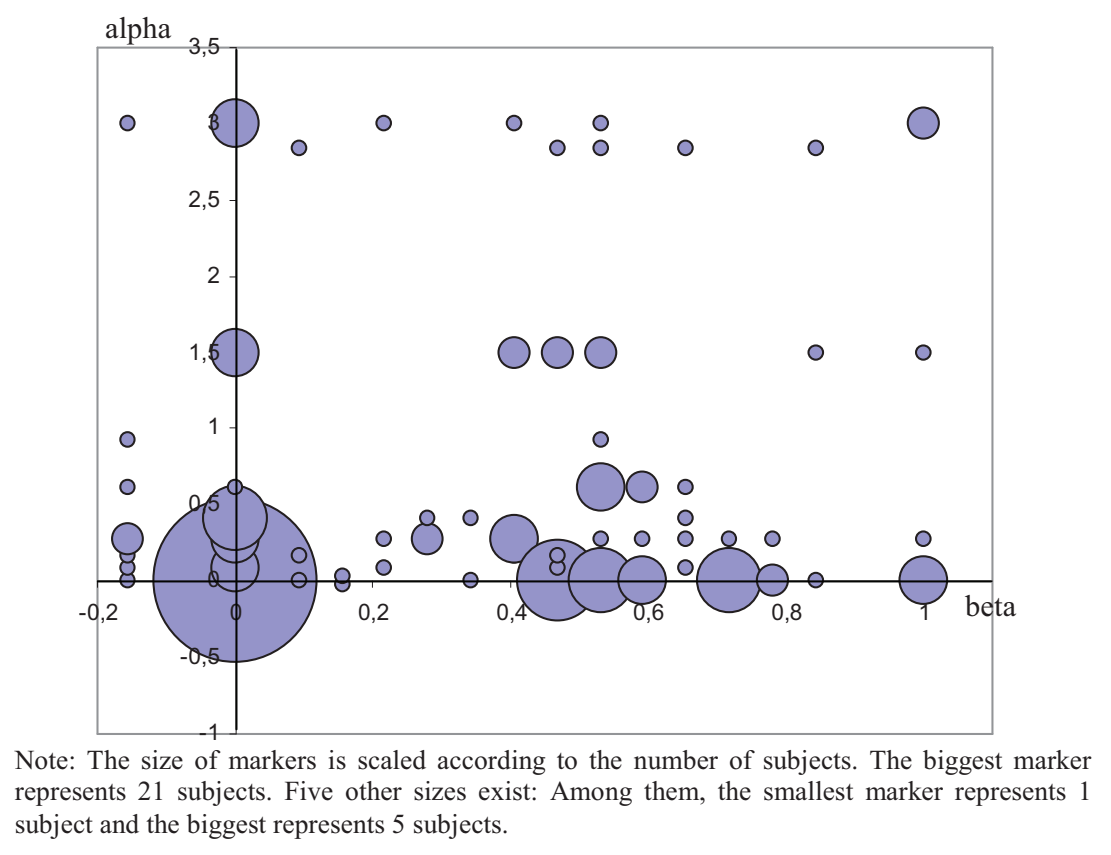

Figure 4: Distribution of $\alpha$ and $\beta$

The distribution of risk preferences for our subject pool is very close to the distribution of Holt and Laury (2002). Table 2 shows the frequency of subjects depending on their degree of risk aversion as defined by Holt and Laury (2002).

\footnotetext{
${ }^{12}$ This last result is surprising with regard to assumptions of the Fehr and Schmidt's model (1999) but our results are in accordance to the experimental results of Blanco, Engelmann and Normann (2007) and Dannenberg, Riechmann, Sturm, and Vogt (2007) who use the same games to measure subjects' inequity aversion degrees.
} 


\begin{tabular}{cccc}
\hline \hline $\begin{array}{c}\text { Number of } \\
\text { safe choices }\end{array}$ & $\begin{array}{c}\text { Range of risk } \\
\text { aversion degrees }\end{array}$ & $\begin{array}{c}\text { Holt and Laury's } \\
\text { classification }\end{array}$ & Frequency \\
\hline $0-1$ & $r<-0.95$ & Highly Risk Lover & 0.00 \\
2 & $-0.95<r<-0.49$ & Very Risk Lover & 0.01 \\
3 & $-0.49<r<-0.15$ & Risk Lover & 0.07 \\
4 & $-0.15<r<0.15$ & Risk Neutral & 0.18 \\
5 & $0.15<r<0.41$ & Slightly Risk Averse & 0.24 \\
6 & $0.41<r<0.68$ & Risk Averse & 0.27 \\
7 & $0.68<r<0.97$ & Very Risk Averse & 0.17 \\
8 & $0.97<r<1.37$ & Highly Risk Averse & 0.04 \\
$9-10$ & $1.37<r$ & Stay in Bed & 0.03 \\
\hline
\end{tabular}

Table 2: Distribution of risk aversion

Risk aversion of subjects is not significantly correlated neither with advantageous inequity aversion (Spearman correlation test, $z=0.0497, p=0.5930$ ) nor with disadvantageous inequity aversion (Spearman correlation test, $z=0.0467, p=0.6157) .{ }^{13}$

\subsection{First mover's choice}

The average contribution of first movers equals 5.97. As shown in table 3 below, three contribution amounts are chosen more often. $18 \%$ of subjects choose to contribute zero to the public good, $15 \%$ choose 5 and $29 \%$ choose 10 .

\footnotetext{
${ }^{13}$ Dubois, Magdalou and Nguyen-Van (2009) use a different method than the design of Blanco, Engelemann and Normann (2006) to measure inequity aversion of subjects. They use the procedure developed by Davidovitz and Kroll (2003) to link risk aversion and inequity aversion. Although they do not differentiate advantageous from disadvantageous inequity aversion, they also find no significant correlation between risk aversion and inequity aversion.
} 


\begin{tabular}{cccc}
\hline \hline Contribution & $\begin{array}{c}\text { Number of } \\
\text { subjects }\end{array}$ & Frequency & $\begin{array}{c}\text { Cumulative } \\
\text { frequency }\end{array}$ \\
\hline 0 & 21 & $17,8 \%$ & $17,8 \%$ \\
1 & 3 & $2,5 \%$ & $20,3 \%$ \\
2 & 1 & $0,8 \%$ & $21,2 \%$ \\
3 & 4 & $3,4 \%$ & $24,6 \%$ \\
4 & 6 & $5,1 \%$ & $29,7 \%$ \\
5 & 18 & $15,3 \%$ & $44,9 \%$ \\
6 & 5 & $4,2 \%$ & $49,2 \%$ \\
7 & 11 & $9,3 \%$ & $58,5 \%$ \\
8 & 9 & $7,6 \%$ & $66,1 \%$ \\
9 & 6 & $5,1 \%$ & $71,2 \%$ \\
10 & 34 & $28,8 \%$ & $100,0 \%$ \\
\hline
\end{tabular}

Table 3: Distribution of contribution decisions

We analyze now which type of preferences, risk or inequity aversion, affects the contribution decision of first movers. We use a tobit model because contribution choices lay between 0 and 10. The first model includes risk aversion, disadvantageous inequity aversion and gender. In the second model, we add advantageous inequity aversion and beliefs of subjects. The proxy for beliefs is the estimation of the other subject's contribution when he is in the first mover position. Table 4 presents the coefficients of the regressions. 


\begin{tabular}{|c|c|c|}
\hline \multicolumn{3}{|c|}{ Dependent variable: contribution decision } \\
\hline & (1) & (2) \\
\hline \multirow[t]{2}{*}{ Gender } & -0.193 & 0.751 \\
\hline & $(1.237)$ & $(0.947)$ \\
\hline \multirow[t]{2}{*}{$\alpha$} & -0.339 & 0.093 \\
\hline & $(0.782)$ & $(0.568)$ \\
\hline \multirow[t]{2}{*}{ Risk aversion } & $-1.021 * *$ & $-0.730 * *$ \\
\hline & $(0.493)$ & $(0.368)$ \\
\hline \multirow[t]{2}{*}{$\alpha *$ Risk aversion } & 0.055 & -0.024 \\
\hline & $(0.139)$ & $(0.102)$ \\
\hline \multirow[t]{2}{*}{$\beta$} & & 0.766 \\
\hline & & $(1.364)$ \\
\hline \multirow[t]{2}{*}{ Belief } & & $1.138 * * *$ \\
\hline & & $(0.147)$ \\
\hline \multirow[t]{2}{*}{ Constant } & $12.271^{* * *}$ & $3.981 *$ \\
\hline & $(2.915)$ & $(2.361)$ \\
\hline $\mathrm{Nb}$ observations & 118 & 118 \\
\hline Left-censured & 21 & 21 \\
\hline Right-censured & 34 & 34 \\
\hline Prob $>\chi^{2}$ & 0.3015 & 0.0000 \\
\hline Pseudo $\mathrm{R}^{2}$ & 0.0094 & 0.1377 \\
\hline
\end{tabular}

Table 4: Contribution decision regressions

Although the first model is not significantly explicative, we observe that risk aversion negatively affects the contribution decision of first movers as predicted theoretically. Crossing over from the safer to the riskier option one decision later in the lottery of Holt and Laury (2002) reduces by 1 the effective contribution of the agent. The theory predicted that disadvantageous inequity aversion should affect negatively the contribution decision as well. However, disadvantageous inequity aversion has no significant effect and risk averse subjects are not more affected by their disadvantageous inequity aversion than risk neutral or risk lover subjects.

In the second model, we take into account the effect of beliefs of subjects via the proxy indicating the estimation subjects make on the contribution decision of the other player as first mover. Confirming previous results in the literature, subjects who believe in the contribution of others are significantly more likely to contribute themselves. With the introduction of beliefs in the regression, the model becomes strongly significant.

These findings are summarized in result 1.

Result 1. As first mover, a subject with higher risk aversion contributes less to the public 
good than others while advantageous and disadvantageous inequity aversion do not have any significant effect. Beliefs on the other's contribution are significantly and positively correlated with first mover's contribution.

When playing as first movers in a sequential public good game, subjects face strategic uncertainty due to their ignorance of the second mover's behavior. Therefore, as predicted, our first result underlines that risk aversion is a strong determinant of subjects' contribution to the public good. In a previous study, Blanco et al. (2006) show that inequity aversion has no role in a simultaneous public good game but they do not measure risk aversion. Our first result suggests that their finding is due to the strategic uncertainty contained in a simultaneous public good game as players are uncertain about the behavior of others. By analyzing the behavior of second movers in our simple design, we can answer the question whether inequity aversion plays a role in the contribution decision of subjects who do not face strategic uncertainty.

\subsection{Second mover's choice}

When playing as second movers, subjects do not face any strategic uncertainty. Subjects decide to contribute the same amount as the first mover or to contribute nothing. Beliefs on others and risk aversion are of no concern. Our experimental design, asking second movers to choose between the zero contribution and the same contribution as the first mover, was chosen in order to keep the design simple and also to identify types. Indeed, only advantageous inequity aversion should affect the decision of subjects as second movers. A subject with $\beta<0.2$ should always choose the zero contribution and an agent with $\beta \geq 0.2$ should always choose the same contribution as the other agent.

Over the 118 participants, we identify five types of subjects. Some subjects are classified as "Free-riders" because they always decide to contribute zero to the public good whatever the contribution of the first mover. The second type represents "Full reciprocators" as they always contribute the same amount as the first mover. Nevertheless, other subjects have a behavior that violates the predictions based on inequity aversion theory: They sometimes choose to contribute the same amount as the other agent and sometimes choose the zero contribution. "Low reciprocators" are subjects who contribute the same amount as the first mover only if the contribution of the first mover is not too high. "High reciprocators" are subjects who reciprocate when the first mover contributes a high amount to the public 
good but free-ride otherwise. Six subjects are classified as "Others" because they do not follow any logic in their switch from a reciprocal to a free-riding behavior or vice-versa. The distribution of subjects' types is written in the following table. ${ }^{14}$

\begin{tabular}{lccc}
\hline \hline & $\begin{array}{c}\text { Number of } \\
\text { subjects }\end{array}$ & Frequency & Average $\beta$ \\
\hline Free-riders & 47 & $39.8 \%$ & 0.17 \\
Full reciprocators & 27 & $22.9 \%$ & 0.55 \\
Low reciprocators & 22 & $18.6 \%$ & 0.39 \\
High reciprocators & 16 & $13.6 \%$ & 0.40 \\
Others & 6 & $5.1 \%$ & 0.23 \\
\hline
\end{tabular}

Table 5: Types of subjects as second movers

We focus our analysis on subjects who verify the inequity aversion theory by choosing always the same amount as the first mover or always the null contribution. These subjects represent the majority with $62.7 \%$ of subjects in total.

We observe that the average advantageous inequity aversion of free-riders is 0.17 while it is 0.55 for reciprocators. The difference is statistically significant (Mann-Whitney Utest, $z=4.668, p<0.0001)$. People who reciprocate to the other's contribution are, on average, more advantageous-inequity averse than agents who free-ride. The following figure strengthens this result. It shows the cumulative distribution of advantageous inequity aversion for reciprocators and free-riders.

\footnotetext{
${ }^{14}$ For more details, the graph of the frequency of the decision to contribute the same amount as the first mover for each contribution of the first mover is given at the end of the appendix.
} 


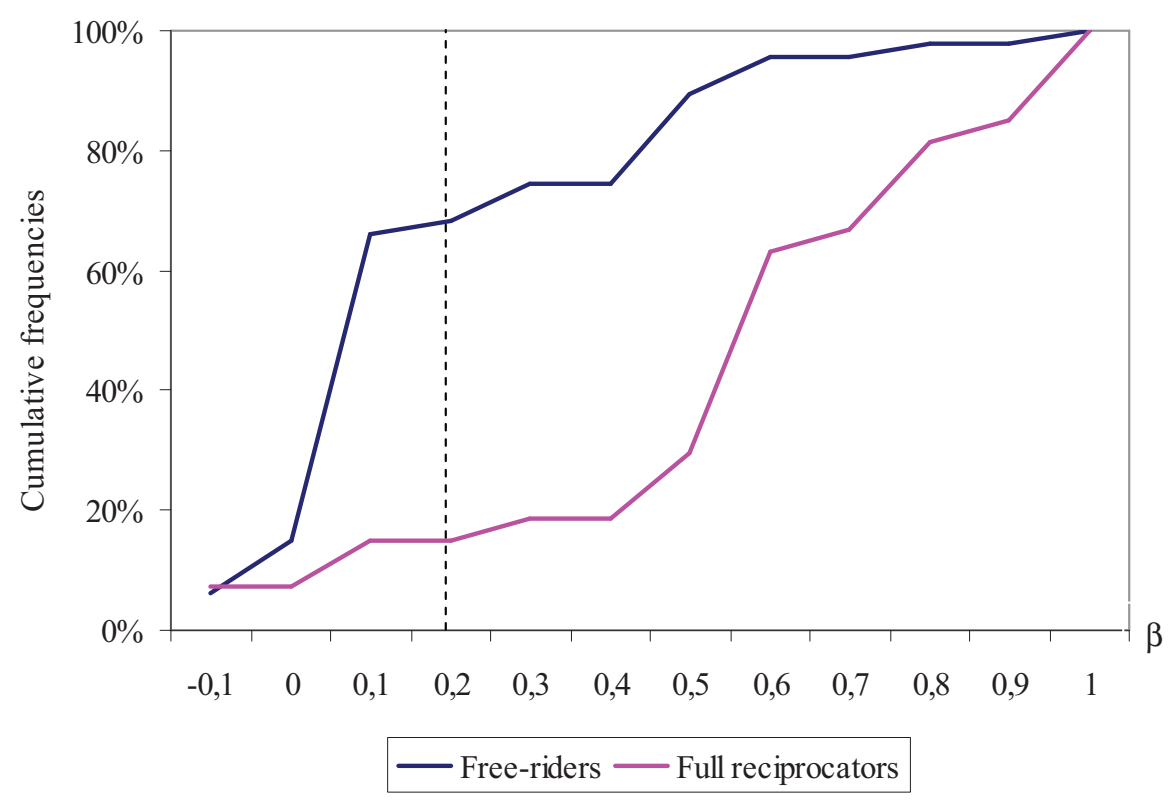

Figure 5: Cumulative distribution of $\beta$ for reciprocators and free-riders

Figure 5 clearly shows that the distribution of advantageous inequity aversion among reciprocators is dramatically different from its distribution among free-riders. We observe that only $15 \%$ of reciprocators have $\beta<0.2$ against a proportion of $68 \%$ for free-riders. This difference is highly significant (Mann-Whitney U-test, $z=4.3848, p<0.0001$ ). This result corroborates the theoretical predictions suggesting that reciprocators should have $\beta \geq 0.2$ and free-riders should have $\beta<0.2$. When playing as second movers, that is without any uncertainty about the other's contribution, advantageous inequity aversion of subjects strongly drives the decision to reciprocate.

We must control by an econometric analysis whether the effect of advantageous inequity aversion on the second mover's choice is significant, controlling for disadvantageous inequity aversion and risk aversion. Disadvantageous inequity aversion should have no effect as the second mover can earn either the same amount as the first mover or more, but never less. Moreover, risk aversion should not have any impact due to the absence of strategic uncertainty. In table 6 , we present probit regressions with marginal coefficients explaining the fact that the subject is a reciprocator and that he is a free-rider. We first consider all subjects to determine the effect of the theoretical threshold of advantageous inequity aversion, i.e. 0.2 , and then we run separated regressions for subjects with advantageous inequity aversion lower than 0.2 and higher or equal than $0.2 .{ }^{15}$

\footnotetext{
${ }^{15}$ In these regressions, we consider subjects of all types previously defined. If we only consider reciproca-
} 


\begin{tabular}{|c|c|c|c|c|c|c|}
\hline & \multicolumn{3}{|c|}{ Dependent variable: to be a reciprocator } & \multicolumn{3}{|c|}{ Dependent variable: to be a free-rider } \\
\hline & All & $\beta<0.2$ & $\beta \geq 0.2$ & All & $\beta<0.2$ & $\beta \geq 0.2$ \\
\hline \multirow[t]{2}{*}{ Gender } & -0.031 & 0.010 & 0.046 & $0.193^{*}$ & 0.135 & 0.127 \\
\hline & $(0.076)$ & $(0.071)$ & $(0.130)$ & $(0.097)$ & $(0.144)$ & $(0.104)$ \\
\hline \multirow[t]{2}{*}{$\beta \geq 0.2$} & $0.274 * * *$ & & & $-0.439 * * *$ & & \\
\hline & $(0.069)$ & & & $(0.087)$ & & \\
\hline \multirow[t]{2}{*}{$\beta$} & & -0.516 & $0.702^{* *}$ & & 0.997 & -0.375 \\
\hline & & $(0.399)$ & $(0.332)$ & & $(0.920)$ & $(0.266)$ \\
\hline \multirow[t]{2}{*}{$\alpha$} & 0.002 & 0.008 & -0.028 & $-0.043 * *$ & $-0.060^{*}$ & -0.007 \\
\hline & $(0.015)$ & $(0.011)$ & $(0.027)$ & $(0.021)$ & $(0.031)$ & $(0.022)$ \\
\hline \multirow[t]{2}{*}{ Risk aversion } & 0.030 & 0.012 & 0.013 & -0.049 & $-0.088^{*}$ & 0.004 \\
\hline & $(0.027)$ & $(0.023)$ & $(0.045)$ & $(0.035)$ & $(0.051)$ & $(0.038)$ \\
\hline $\mathrm{Nb}$ observations & 118 & 51 & 67 & 118 & 51 & 67 \\
\hline Prob $>\chi^{2}$ & 0.0068 & 0.4926 & 0.1942 & 0.0000 & 0.0372 & 0.2945 \\
\hline Pseudo $\mathrm{R}^{2}$ & 0.1115 & 0.1214 & 0.0704 & 0.1854 & 0.1514 & 0.0692 \\
\hline
\end{tabular}

Table 6: Reciprocal decision regressions

The threshold of advantageous inequity aversion theoretically defined has a significant and strong effect that confirms the predictions. Indeed, a subject with $\beta \geq 0.2$ is $27 \%$ more likely to be a reciprocator than others and $44 \%$ less likely to be a free-rider. The effect of advantageous inequity aversion as a continuum is significant and positive in determining whether the subject is a reciprocator or not only if the subject has $\beta \geq 0.2$. In this case, a subject with $\beta$ higher than others' advantageous inequity aversion by 0.1 has a probability to be a reciprocator higher by $7 \%$. In all other cases, continuous $\beta$ does not have any significant impact. The effect of risk aversion is not significant or with a very low impact. Therefore, when subjects play as second movers, that is without any strategic uncertainty, the impact of advantageous inequity aversion on the decision to reciprocate is strong and highly significant, which corroborates theoretical predictions. The following result summarizes our finding when subjects play as second movers.

Result 2. As second mover, a subject makes his choice between contributing the same tors and free-riders, the effect of advantageous inequity aversion is even stronger and has more explanatory power. As the graph already only considers reciprocators and free-riders and the conclusion is clear, we include all the participants in the econometric regressions. Moreover, we were careful to add every explanatory variable sequentially to control for collinearity. As it appears that marginal coefficients are not changed with the introduction of a new variable, we only reported here the final regressions. 
amount as the first mover and contributing nothing to the public good mainly according to his advantageous inequity aversion: A subject with advantageous inequity aversion higher than 0.2 is more likely to reciprocate than others. Risk aversion and disadvantageous inequity aversion do not have any impact on this decision.

The hypothesis of the Fehr and Schmidt model (1999) suggesting that people with high advantageous inequity aversion are more likely to cooperate and then to contribute in a public good game is supported by our data. Indeed, for this hypothesis to be correctly tested, strategic uncertainty must be removed from the public good game. This is needed to focus on the pure effect of social preferences neutralizing the effect of individual characteristics related to uncertainty. This is what we did when analyzing the second mover's behavior in the sequential public good game. We found in this case that among risk aversion and advantageous and disadvantageous inequity aversion, only advantageous inequity aversion has a strong and significant effect. The individual preference that mainly explains contribution in a public good game without strategic uncertainty is advantageous inequity aversion of agents. Our result suggests that the Fehr and Schmidt model's predictions are verified if social preferences are the unique type of preferences at stake.

\section{Conclusion}

When deciding to contribute to a public good, some people observe first the behavior of individuals' in their neighborhood. To properly understand the behavior of individuals regarding their investment in a public good, we must differentiate individuals who make their decision without any information on others' behavior and individuals who can observe the investment of others. Therefore, we conducted a sequential public good game experimentally with all agents playing as first and second movers, using the strategy method. Social preferences and risk preferences are the two intrinsic preferences we were interested in. Predictions were clear: First movers with high risk aversion or high disadvantageous inequity aversion should contribute to the public good less than others. Second movers with a sufficiently high degree of advantageous inequity aversion should contribute more than others.

We find that theoretical predictions are mainly supported by the data. Regarding first movers' behavior, we find that the higher the risk aversion of a subject, the lower his 
contribution to the public good. In addition to intrinsic preferences, first movers are also influenced by their beliefs on others' behavior. Analyzing second movers' decisions, the data show that the main source of reciprocity is advantageous inequity aversion. Subjects sufficiently advantageous-inequity averse are more likely to reciprocate by contributing the same amount as the first mover and less likely to free-ride. Besides, disadvantageous inequity aversion and risk aversion, as predicted, do not have any significant impact. This result supports the predictive power of the Fehr and Schmidt model (1999) to explain reciprocity as soon as there is no strategic uncertainty in the game. It is however relevant to note that while the inequity aversion theory predicts that a specific subject should either always reciprocate or always free-ride, around one third of the subjects do not behave in this manner.

Our results may have some implications in economic policy or in organization management. For instance, they suggest that it may be worthwhile to improve transparency or communication for risk averse or advantageous inequity averse individuals to improve their cooperative behavior when other people are cooperative too. Although it is not possible to observe individuals' preferences, we know that subjects self-select in different jobs or firms depending on their risk aversion (Bellemare and Shearer, 2006, Bonin et al., 2006, Grund and Sliwka, 2006). No evidence on business data is available at the moment sustaining self-selection according to individuals' social preferences but it is found in laboratory experiments (Cabrales et al., 2008, Dohmen and Falk, 2006, Teyssier, 2008). Therefore, a higher transparency for some specific jobs or firms is suggested. It seems useless to set up costly communication activities when people receiving the information are selfish.

Another contribution of this study is more methodological. The results show that agents' behavior can be consistent between games although the context is different. It then suggests the use of experimental within-subjects analyses. Nevertheless, while it seems clear how to elicit risk aversion in experiments, an important debate concerns the elicitation of social preferences. It remains unclear at the moment which games could elicit the best trust, reciprocity and inequity preferences independent of the context or, at least, which games would be the best measure for each type of context, provided that contexts can be classified. In our opinion, this is an important point and future research should go in this direction. 


\section{References}

Bellemare, C., and B. S. Shearer (2006). "Sorting, Incentives and Risk Preferences: Evidence from a Field Experiment." IZA Discussion Paper, $\mathrm{n}^{\circ} 2227$.

Blanco, M., D. Engelmann, and H.T. Normann (2007). "A Within-Subject Analysis of Other-Regarding Preferences." Mimeo, Royal Halloway College, University of London.

Bohnet, I., and R. Zeckhauser (2004). "Trust, Risk and Betrayal." Journal of Economic Behavior and Organization, 55, pp. 467-84.

Bonin, H., T. Dohmen, A. Falk, D. Huffman, and U.Sunde (2007). "Cross-Sectional Earnings Risk and Occupational Sorting: The Role of Risk Attitudes." Labour Economics, $14(6)$, pp. 926-37.

Cabrales, A., R. Miniaci, M. Piovesan, and G. Ponti (2008). "Social Preferences and Strategic Uncertainty: An Experiment on Markets and Contracts." Working Paper, ${ }^{\circ}$ 08-06, University of Copenhagen.

Cooper, R., D. V. Dejong, R. Forsythe, and T. W. Ross (1992). "Forward induction in coordination games." Economics Letters, 40(2), pp. 167-72.

Croson, R. (1998). "Theories of Altruism and Reciprocity: Evidence from Linear Public Goods Games." Working Paper n 98-11-04, The Warton School of the University of Pennsylvania.

Dannenberg, A., T. Riechmann, B. Sturm, and C. Vogt (2007). "Inequity Aversion and Individual Behavior in Public Good Games: An Experimental Investigation." $Z E W$ Working Paper, $\mathrm{n}^{\circ}$ 07-034.

Davidovitz, L., and Y. Kroll (2004). "On the Attitudes Toward Inequality." Research on Economic Inequality, 11, pp. 137-48.

Dohmen, T., and A. Falk (2006). "Performance Pay and Multi-Dimensional Sorting: Productivity, Preferences and Gender." IZA Discussion Papers, n 2001.

Dubois, D., B. Magdalou and P. Nguyen-Van (2009). "Risk and Inequality Aversion in Social Dilemmas." LAMETA Working Paper, n DR2009-02.

Falk, A., E. Fehr, and U. Fischbacher (2003). "On the nature of fair behavior." Economic Inquiry, 41 (1), pp. 2026.

Falk, A., and U. Fischbacher (2006). "A theory of reciprocity." Games and Economic Behavior, 54(2), pp. 293-315.

Fehr, E., and K. M. Schmidt (1999). "A Theory of Fairness, Competition, and Cooperation." Quarterly Journal of Economics, 114(3), pp. 817-68.

Fischbacher, U., and S. Gächter (2009). "Social Preferences, Beliefs, and the Dynamics of Free Riding in Public Goods." American Economic Review, forthcoming.

Gächter, S., and E. Renner (2006). "The effects of (Incentivized) Belief Elicitation in Public Good Experiments." CeDEx Working Paper, n² 2006-16. 
Greiner, B. (2004). "An Online Recruitment System for Economic Experiments." In Kurt Kremer, Volker Macho (eds.). Forschung und wissenschaftliches Rechnen, GWDG Bericht 63, Gttingen : Ges. fr Wiss. Datenverarbeitung, 2003, pp. 79-93.

Grund, C. and D. Sliwka (2006). "Performance Pay and Risk Aversion." IZA Discussion Paper, $n^{\circ} 2012$.

Güth, W., R. Schmittberger, and B. Schwarze (1982). "An Experimental Analysis of Ultimatum Bargaining." Journal of Economic Behavior and Organization, 3, pp. 367-88.

Heinemann, F., R. Nagel, and P. Ockenfels (2009). "Measuring Strategic Uncertainty in Coordination Games." Review of Economic Studies, 76, pp. 181221.

Holt, C. A., and S. K. Laury (2002). "Risk Aversion and Incentive Effects."' American Economic Review, 92(5), pp. 1644-55.

Lazear, E. P., U. Malmendier, and R. Weber (2006). "Sorting in Experiments with Application to Social Preferences." NBER Working Paper, ${ }^{\circ} 12041$.

Ledyard, J. (1995). "Public Goods: A Survey of Experimental Research." In: Kagel, J. H., and A. E. Roth, ed., Handbook of Experimental Economics, Princeton University Press, pp. 111-81.

McCabe, K., M. Rigdon, and V. Smith (2003). "Positive reciprocity and intentions in trust games." Journal of Economic Behavior and Organization, 52, pp. 26775.

Offerman, T. (1997). Beliefs and Decision Rules in Public Good Games. Theory and Experiments. Dordrecht: Kluver.

Offerman, T., J. Sonnemans, and A. Schram (1996). "Value Orientations, Expectations and Voluntary Contributions to Public Goods." Economic Journal, 106, pp. 817-45.

Offerman, T., J. Sonnemans, and A. Schram (1996). "Expectation Formation in StepLevel Public Good Games" Economic Inquiry, 39, pp. 250-69.

Orbell, J., and R. M. Dawes (1991). "A Cognitive Miser Theory of Cooperators Advantage." American Political Science Review, 85, pp. 51528.

Schechter, L. (2007). "Traditional Trust Measurement and the Risk Confound: An Experiment in Rural Paraguay." Journal of Economic Behavior and Organization, 62, pp. 272-92.

Selten, R. (1967). "Die Strategiemethode zur Erforschung des eingeschränkt rationalen Verhaltens im Rahmen eines Oligopolexperiments." In: H. Sauermann, ed., Beiträge zur experimentellen Wirtschaftsforschung, Vol. 1), Tübingen: J.C.B. Mohr (Siebeck), pp. 13668.

Sobel, J. (2005). "Interdependent Preferences and Reciprocity." Journal of Economic Literature, XLIII, pp. 392-436.

Teyssier, S. (2008). "Experimental Evidence on Inequity Aversion and Self-Selection between Incentive Contracts." GATE Working Paper, nº 08-21.

Zeiliger, R. (2000) A Presentation of Regate, Internet Based Software for Experimental Economics. http://www.gate.cnrs.fr/ ${ }^{\sim}$ zeiliger/regate/RegateIntro.ppt, GATE, 2000. 


\section{Appendix}

\section{Instructions}

You are about to participate in an experiment on decision-making organized for the GATE research institute. During this session, you can earn money. The amount of your earnings depends on your decisions and on the decisions of the participants you will have interacted with. The experiment is composed of four independent sections. In every section, you will make one or several decisions. You will make your decisions without knowing the other participants' decisions in the previous sections. Note that the other participants do not know your decisions either.

The first section is realized in paper form. The result of the first section requires an individual random draw that will take place at the end of the session to determine your earnings.

Your final profit also depends on three other sections. The section considered for your earnings computation will be randomly determined by the computer software. Every section has the same probability of being selected. At the end of the session, the result of this draw will be individually announced, as well as your payoff in this section. Your total earnings will be individually announced and paid in cash in a separate room in order to preserve confidentiality. You will additionally receive a show-up fee of 3 euros.

During the entirety of the session, you cannot communicate.

Thank you for your participation.

\section{Section 1}

The attached sheet of paper shows ten decisions. Each decision is a paired choice between "option a" and "option b". You will make ten choices and record these in the column on the right, but only one of them will be used in the end to determine your additional earnings. Let us explain how these choices will affect your earnings.

Here is a ten-sided die that will be used to determine this payoff. The faces are numbered from 1 to 10 (the " 0 " face of the die will serve as 10). When you receive your earnings at the end of the experiment next week, as you will come to the other office, you will throw this die twice : once to select one of the ten decisions to be used and a second time to determine what your payoff is for the option you chose, a or b, for the particular decision selected.

Even though we ask you to make ten decisions, only one of these will end up affecting your earnings. However, you will not know in advance which decision will be used. Of course, each decision has an equal chance of being used in the end.

- Look at decision 1

Option a pays $€ 2$ if the throw of the dice is 1 , and it pays $€ 1.6$ if the throw is $2-10$.

Option b yields $€ 3.85$ if the throw of the dice is 1 and it pays $€ 0.1$ if the throw is $2-10$.

- Look at decision 2

Option a pays $€ 2$ if the throw of the dice is 1 or 2 , and it pays $€ 1.6$ if the throw is $3-10$.

Option b yields $€ 3.85$ if the throw of the dice is 1 or 2 and it pays $€ 0.1$ if the throw is $3-10$.

- The other decisions are similar, except that as you move down the table, the chances of a higher payoff for each option increase. In fact, for decision 10 in the bottom row, the dice will not be needed since each option pays the highest payoff for sure, so your choice here is between $€ 2$ and $€ 3.85$. 
To summarize,

- You will make ten choices. For each decision row, you will have to choose between option $\mathrm{a}$ and option b. You may choose a for some decision rows and b for other rows. You may change your decisions and make them in any order.

- Next week, when you come to the other room to receive your earnings from the experiment, you will throw the ten-sided die to select which of the ten decisions will be used.

- Then, you will throw the die again to determine your money earnings for the option you chose for that decision.

The earnings for this choice will be added to your other earnings, and you will be paid all earnings in cash at the end of the experiment next week.

If you have any question, please raise your hand. Your questions will be answered in private. Please do not talk with anyone. 


\section{Section 1}

PARTICIPANT NUMBER :

NAME OF YOUR COMPUTER :

\section{DATE :}

Please indicate for each of the following 10 decisions if you choose Option a or Option b.

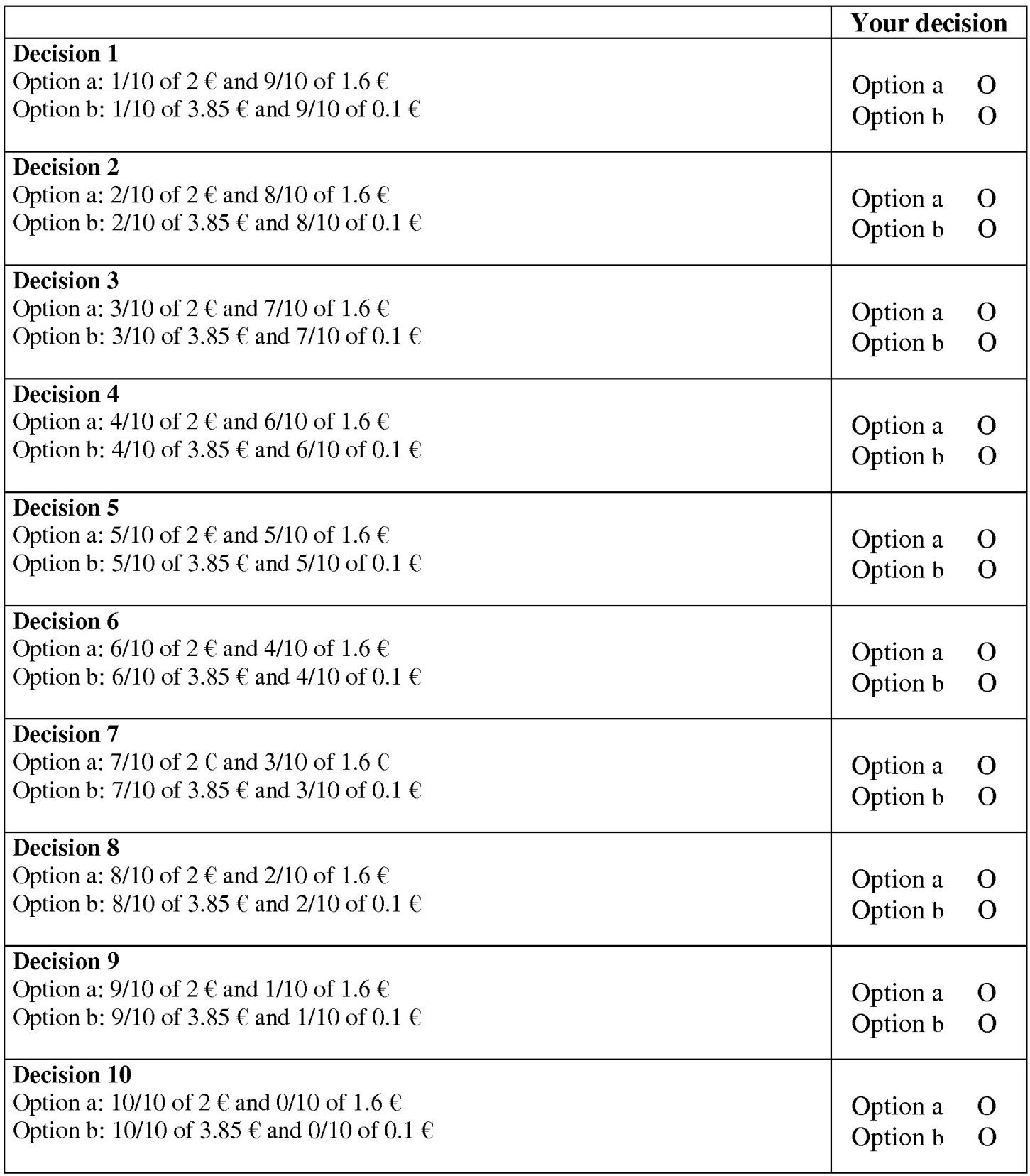

Sections 2, 3 and 4 are conducted via computer. Your earnings will be calculated in points,

$$
4 \text { points }=1 \text { euro }
$$

We remind you that one of the sections 2 and 3 will be randomly selected by the computer software to determine your earnings. Each section has the same probability to be selected. 


\section{Section 2}

\section{This section is independent of the previous section.}

In this section, the situation is the following :

- Person B will choose between two options : either to participate in the game whose rules are described below, or to receive 5 points and not to participate in the game.

- In the game, person A must choose between two earnings distributions between herself and person B in 21 different decision problems. Person B can only accept person A's decisions.

- You make your decisions under the role of the person A and under the role of the person B. The roles of the persons A and B will be randomly determined by the computer software once you have made your decisions.

The decision problems of the game will be presented in a table.

Example : Decision 7 is presented as follows :

\begin{tabular}{|l|ll|}
\hline Decision 7 & Option a & O \\
Option a: Your payoff is 7 pts and the payoff of person B is 7 pts & Option b & O \\
Option b: Your payoff is 18 pts and the payoff of person B is 2 pts &
\end{tabular}

You make your decisions in the role of person A :

If you choose option a, you and person $\mathrm{B}$ will receive 7 points each. If you choose option b, you decide to keep 18 points for yourself and the payoff of person $\mathrm{B}$ will be 2 points.

The other decisions are similar, except that as you move down the table, the payoff of each person under option a is increased.

For example, decision 10 is presented as follows :

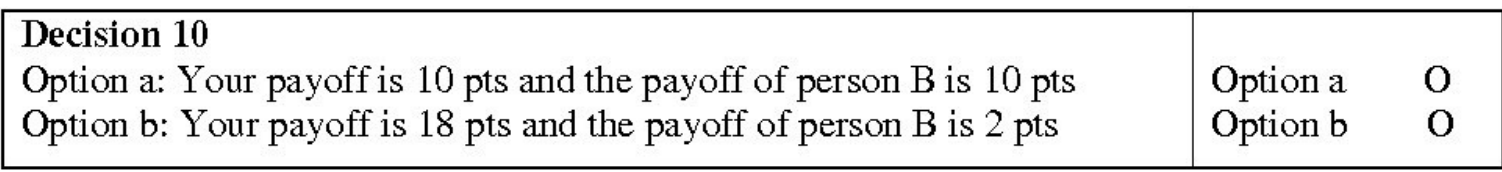

You will choose an option ( $\mathrm{a}$ or b) in each of the twenty-one lines you will see on the screen.

If this section is selected to determine your earnings, the computer software will affect you randomly with another participant in the room once your choices are done and will give you a role. The matching and the role attribution will remain anonymous.

The computer software will randomly select one of the decisions.

You make your decisions in the role of person A and also in the role of person B.

Your earnings are determined as follows :

- If you receive role B :

- If you have chosen not to participate in the game, you will earn 5 points.

- If you have chosen to participate in the game, you will earn the amount that person A with whom you are paired has chosen for person B in the decision selected by the computer software. 
- If you receive role A, you will earn the amount you have chosen for yourself in the decision selected by the computer software.

Example of earnings calculation :

Decision 7 is the decision selected by the computer software.

If person $\mathrm{B}$ decides to participate in the game

- If person A has chosen option a

Earnings of person A are : 7

Earnings of person B are : 7

- If person A has chosen option b

Earnings of person A are : 18

Earnings of person B are : 2

If person $\mathrm{B}$ decides not to participate in the game

- If person A has chosen option a

Earnings of person A are : 7

Earnings of person $\mathrm{B}$ are : 5

- If person $\mathrm{A}$ has chosen option $\mathrm{b}$

Earnings of person A are : 18

Earnings of person B are : 5

\section{Section 3}

\section{This section is independent of the previous section.}

In this section, the situation is the following :

- Person A will choose a distribution (only one) over the twenty-one payoff distributions available between herself and person B.

- Person B knows that person A has been asked to make this decision. B can either accept or reject the distribution chosen by A. If person B accepts the distribution proposed by person $\mathrm{A}$, this payoff distribution is implemented. If person $\mathrm{B}$ rejects the offer, the two persons, $\mathrm{A}$ and $\mathrm{B}$, receive nothing.

- Person B chooses between accepting and rejecting the distribution proposed by person A for each of the twenty-one available distributions. Person B must choose an option (to accept the distribution or to reject the distribution) in each of the twenty-one lines on the screen.

If this section is selected to determine your earnings, the computer software will match you randomly with another participant in the room once your choices are done and will give you a role. The matching and the roles attribution will remain anonymous.

You will make your decisions in the role of person A and also in the role of person B. 
- If you receive role A, you will earn the amount that you have chosen for yourself if the person B with whom you are matched accepts your offer. If person B rejects the offer, you and person $\mathrm{B}$ will earn nothing.

- If you receive role $\mathrm{B}$, you will earn the amount that the person $\mathrm{A}$ with whom you are matched has chosen for B if you have accepted the offer. If you have rejected this offer, person $\mathrm{A}$ and you earn nothing.

\section{Section 4}

This section is independent of the previous section.

In this section, the situation is the following :

- Person A receives 10 points. In the following, we will call this amount the "endowment".

- Person A will decide how to use her endowment: A decides how much of the 10 points she wants to contribute to a project (from 0 to 10) and how much she wants to keep for herself.

- Person B receives an endowment of 10 points.

- Person B must choose between two possible contributions to the project as she faces ten different contributions of person A.

The decision problems of person $\mathrm{B}$ will be presented in a table.

Example: Decision 7 is presented as follows :

\section{Decision 7: A contributes 7 pts}

Option a: Your contribution is $7 \mathrm{pts}$

Option b: Your contribution is $0 \mathrm{pt}$
Option a $\quad \mathrm{O}$

Option b $\quad \mathrm{O}$

If in this specific decision problem you choose option a, it means that you decide to contribute the same amount as person A: you decide to contribute 7 points when she contributes 7 points. If you choose option $\mathrm{b}$, it means that you decide to contribute 0 points to the project when person A contributes 7 points.

The other decisions are similar, except that as you move down the table, the contribution of person A is increased.

You choose an option ( $\mathrm{a}$ or b) for each of the eleven lines on the screen.

If this section is selected to determine your earnings, the computer software will match you randomly with another participant in the room once your choices are done and will give you a role. The matching and the roles attribution will remain anonymous.

Payoffs of each participant are determined as follows:

Payoff $=\mathbf{1 0}-$ your contribution to the project

$+0.8 *$ (your contribution to the project + the other person's contribution to the project)

This formula shows that your payoff in this section consist of two parts: 1) the share of the 
endowment you keep for yourself 2) the return of the project, that is $80 \%$ of the total contribution of the two persons who are matched together You will make your decisions in the role of person A and also in the role of person B.

- If you receive role A, your effective contribution to the project is the contribution decision you chose under role A.

- If you receive role $\mathrm{B}$, your effective contribution to the project is the contribution you chose (option a or b) conditional on the contribution of the person A with whom you are matched.

- The earnings of person A and of person B are calculated according to the payoff formula described above.

Examples :

Person A contributes 4 points to the project.

- If person $\mathrm{B}$ decides to contribute 0 points when $\mathrm{A}$ contributes 4 points :

Earnings of person $\mathrm{A}=10-4+0.8 *(4+0)=9.2$

Earnings of person $\mathrm{B}=10-0+0.8 *(4+0)=13.2$

- If person $\mathrm{B}$ decides to contribute 4 points when $\mathrm{A}$ contributes 4 points :

Earnings of person $\mathrm{A}=10-4+0.8 *(4+4)=12.4$

Earnings of person $\mathrm{B}=10-4+0.8 *(4+4)=12.4$

Person A contributes 9 points to the project.

- If person B decides to contribute 0 points when A contributes 9 points :

Earnings of person $\mathrm{A}=10-9+0.8^{*}(9+0)=8.2$

Earnings of person $\mathrm{B}=10-0+0.8 *(9+0)=17.2$

- If person $\mathrm{B}$ decides to contribute 9 points when A contributes 9 points :

Earnings of person $\mathrm{A}=10-9+0.8 *(9+9)=15.4$

Earnings of person $\mathrm{B}=10-9+0.8 *(9+9)=15.4$ 
Frequency of reciprocal decisions depending on the type of second movers

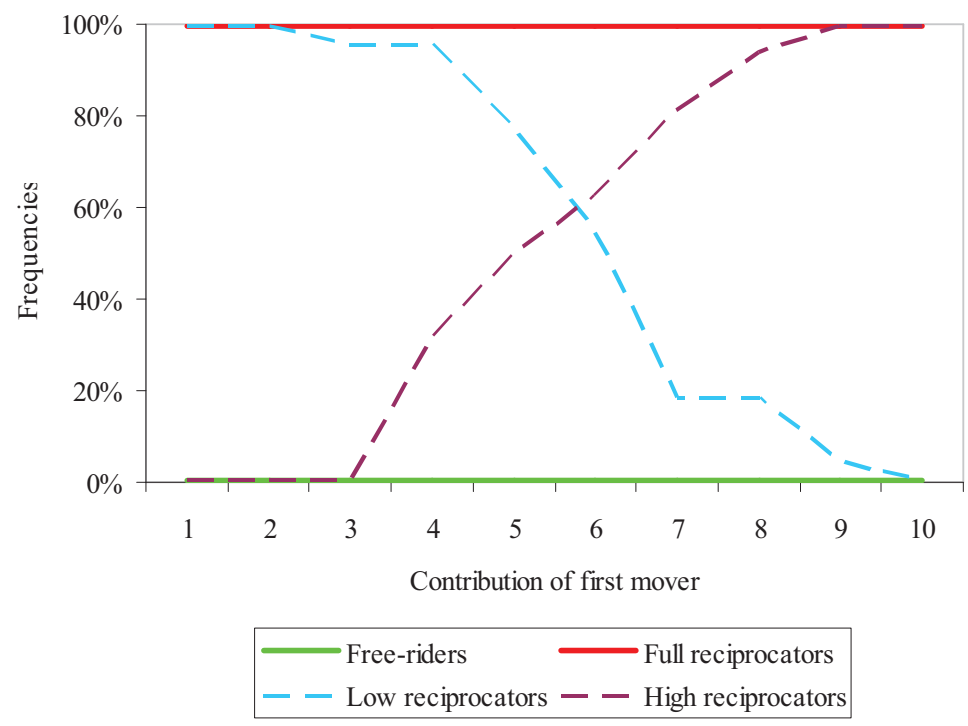

